
\section{Case report:
cobblestone}

Department of

Genitourinary

Medicine, Leicester

Royal Infirmary,

Leicester LE1 5WW

$S$ Bhaduri

P G Fisk

Department of

Dermatology

G Johnston

Correspondence to: Dr P Fisk

PFisk@uhl.trent.nhs.uk

Accepted for publication 19 April 2000

\title{
Pyogenic granuloma of the penis-don't squeeze them
}

\author{
S Bhaduri, P G Fisk, G Johnston
}

We report the case of a pyogenic granuloma on the shaft of the penis presenting with active bleeding secondary to attempted expression. Previously reported cases have documented such lesions on the prepuce and glans.

(Sex Transm Inf 2000;76:217)

Keywords: penis; granuloma

\section{Case report}

A 31 year old man presented to the department of genitourinary medicine in Leicester with a 2 week history of a lesion on the shaft of the penis. There was no history of recent trauma although he had attended the unit 5 years earlier with inguinal lymphadenopathy related cat scratch fever. The patient initially presented to a general practitioner who considered the lesion to be a " blood blister" and suggested that the lesion be "squeezed."

Unfortunately, having complied with these instructions, the patient noticed extensive bleeding from the lesion with a subsequent increase in size. He immediately contacted his general practitioner who suggested referral to the department of genitourinary medicine.

On examination at the unit, a well demarcated raised vascular lesion was noted on the shaft of the penis that was still actively bleeding (fig 1). A clinical diagnosis of a pyogenic granuloma was made and the patient was referred for a complete excision of the lesion on the same day. Histologically the diagnosis was

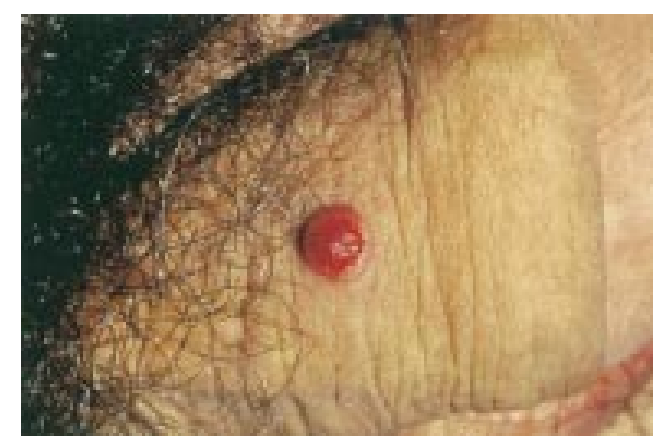

Figure 1 Pyogenic granuloma on the shaft of the penis. confirmed. On follow up, the patient noted no recurrence.

\section{Discussion}

Penile pyogenic granulomas have been reported previously, ${ }^{1-3}$ although the lesions have been confined to the prepuce or glans as opposed to the shaft of the penis (as in our patient). The lesions are usually solitary and rapidly growing and bleed easily, often occurring at the site of minor trauma of the skin. ${ }^{1}$ The usual sites of occurrence are exposed surfaces such as hands, forearms, and on the face although it may also occur in the oral mucosa, palms, soles, and nail folds. ${ }^{4}$

The pathogenesis is probably related to a reaction to trauma or injury and early appearances histologically resemble granulation tissue. This in turn gives rise to a distinctive lobular arrangement of capillaries in a fibroblastic stroma. In other words, the lesion is neither pyogenic nor a granuloma.

Treatment options include curettage and cauterisation, diathermy coagulation of the base, or excision; the latter method may minimise recurrence. ${ }^{2}$

In summary, we report a case of a pyogenic granuloma arising on the shaft of the penis, managed by an excisional biopsy. We recommend that the lesion not be squeezed!

Contributors: SB saw the patient and wrote the paper; PGF saw the patient, was the consultant in charge, and made the diagnosis; GJ confirmed the diagnosis on biopsy in dermatology.

1 Tomasini C, Puiatti P, Bernengo MG. Multiple pyogenic granuloma of the penis. Sex Trans Inf 1995;74:221-2.

2 Walzman M, Kundu A, Fraser I. Pyogenic granuloma of the penis- a rare entity. Genitourin Med 1998;71:43-4.

3 Maeda Y, Izutani T, Yonese J, et al. Pyogenic granuloma of the glans penis. Br F Urol 1998;82:771-2.

the glans penis. Br f Urol 1998;82:771-2.
4 Hare PJ. Granuloma pyogenicum. Br f Derm 1970;83:51531 . 